\title{
BMJ Open Is an obesity simulation suit in an undergraduate medical communication class a valuable teaching tool? A cross- sectional proof of concept study
}

\author{
Anne Herrmann-Werner, ${ }^{\odot}$ Teresa Loda, ${ }^{\odot}$ Lisa M Wiesner, \\ Rebecca Sarah Erschens, ${ }^{\circ}$ Florian Junne, ${ }^{\circledR}$ Stephan Zipfel ${ }^{\odot}$
}

To cite: Herrmann-Werner A, Loda T, Wiesner LM, et al. Is an obesity simulation suit in an undergraduate medical communication class a valuable teaching tool? A cross-sectional proof of concept study. BMJ Open 2019;9:e029738. doi:10.1136/ bmjopen-2019-029738

- Prepublication history for this paper is available online. To view these files, please visit the journal online (http://dx.doi org/10.1136/bmjopen-2019029738).

Received 11 February 2019 Revised 11 June 2019 Accepted 11 June 2019

Check for updates

(C) Author(s) (or their employer(s)) 2019. Re-use permitted under CC BY-NC. No commercial re-use. See rights and permissions. Published by BMJ.

Department of Psychosomatic Medicine and Psychotherapy, University Hospital Tuebingen, Tuebingen, Germany

Correspondence to Teresa Loda; teresa.loda@med.unituebingen.de

\section{ABSTRACT}

Objective With the growing prevalence of overweight and obesity, medical students should be prepared to engage in weight management and obesity-related communications in order to prevent patients from having stigmatising experiences. In addition, medical students should have training to reduce anti-fat prejudices.

Design Cross-sectional proof of concept study.

Setting University Hospital Tuebingen, Germany. Participants 246 participants (207 second-year medical students, 13 standardised patients (SPs) and 22 teachers) took part in the study.

Primary and secondary outcome measures The primary outcome was the assessment of degree of reality of the encounter with the SP wearing an obesity simulation suit (OSS). The secondary outcome was the evaluation of students' awareness and prejudice against patients with obesity in a simulated role play. Additionally, a description of the advantages and disadvantages when using such a teaching tool is delivered.

Results The OSS contributed to a realistic perception of the patient group depicted in a role play according to students, teachers and SPs. OSS body mass index estimation by students, teachers and SPs correctly was over $30 \mathrm{~kg} / \mathrm{m}^{2}$-thus in the range of obesity. In a selected subscale of the Anti-Fat Attitudes Test, students showed significantly stronger anti-fat stigmatisation compared with teachers and SPS.

Conclusions An OSS worn by an SP is a valuable teaching tool to raise awareness about patients with obesity. It gives a realistic picture of the encounter. Stigmatisation was low in general but was especially present in the students. Further research should include intervention studies to address this issue.

\section{INTRODUCTION}

Weight issues are a common problem. Over $50 \%$ of German adults aged 18 to 79 years can be classified as being overweight (body mass index $(\mathrm{BMI}) \geq 25.0 \mathrm{~kg} / \mathrm{m}^{2}$ ) and $23 \%$ as being obese $\left(\right.$ BMI $\left.\geq 30 \mathrm{~kg} / \mathrm{m}^{2}\right){ }^{1}$ Increased weight can cause multiple health problems such as hypertension, type 2 diabetes, infertility or chronic back pain. ${ }^{2}{ }^{3}$ Both general
Strengths and limitations of this study:

- This study is cross sectional and proof of concept.

- Observational investigation of a simulated patientphysician encounter in an undergraduate teaching class.

- Evaluation of an obesity simulation suit as a teaching tool including simulated authenticity, didactic profit and possible difficulties in the perspective of students, standardised patients and teachers in order to increase the degree of fidelity in the simulated situation.

- The study was conducted only in a simulated environment and not with real patients with obesity

and abdominal obesity are associated with the risk of premature death, and can affect psychological well-being and self-esteem. ${ }^{45}$ All these negative implications of high body weight highlight the need for appropriate healthcare for patients with obesity, particularly as the prevalence of obesity continues to increase. ${ }^{6}$

Alongside the health risks related to obesity, stigmatisation plays an important role for patients who are overweight or obese. ${ }^{7-9}$ Both conditions are imposed with a socially accepted stigma-when only implicitly measured via gaze behaviour, ${ }^{10}$ for highly experienced human resource professionals when deciding who to hire for $\mathrm{a} \mathrm{job}^{9}$ and also in the context of public health institutions. ${ }^{7-9}$ Furthermore, overweight and obesity affect the patient-physician communication and interaction (eg, doctor shopping or losing trust in their attending physicians) due to stigmatisation. ${ }^{11-13}$ This stigmatisation makes it more difficult for people with obesity to seek and find help; additionally, it negatively impacts prevention and therapy, thereby imposing consequences for the health of affected individuals. ${ }^{8}$ Furthermore, health 
professionals have been found to communicate in a less patient-oriented and respectful way with patients with obesity; in particular, they take less time for consultation and explanations, instead attributing the patients' problems and symptoms to their weight rather than to other potential causes. ${ }^{14}$ This seems not only true for physicians, but also for health professionals from different fields specialised in the treatment of obesity, including nursing, physiotherapy, internal medicine or nutrition coaching. ${ }^{15-21}$ With these factors in mind, it is crucial to make medical students aware of the stigma towards patients with obesity by healthcare providers and to prepare them for appropriate interactions towards this population. Encounters with standardised patients (SPs) can be seen as an appropriate simulated teaching scenario, offering advantages such as availability, the possibility to simulate a range of different conversations over time, as well as safe exposure to negative events for students and SPs. ${ }^{22}{ }^{23}$ However, it could be shown that aligning the SP's phenotype to the role is critical, otherwise the perceived degree of reality might be decreased and thus not considered an authentic learning tool by students. ${ }^{24}$ To simulate a highly realistic situation, we designed a scenario with an SP wearing an obesity simulation suit (OSS) in order to authentically simulate a patient with type 2 diabetes.

Although current literature features broad discussions about the best terminology to describe the tool of an OSS ('fat suit', ${ }^{25}$ 'obesity suit', ${ }^{26}$ 'simulation suit', ${ }^{27-29}$ 'weight suit ${ }^{30}$ ), we decided to use the term 'obesity simulation suit' as we consider it the most neutral term in the context of stigmatisation.

To the best of our knowledge, the evaluation of an OSS used in undergraduate medical education has not been used before. In similarly designed studies, the situation has involved either students wearing the OSS themselves for self-experience ${ }^{31}$ or actual SPs with obesity, which entails the potential danger of issues becoming too personal for the $\mathrm{SP}^{32}$

The goals of the study were: (1) to assess the degree of reality of the encounter with an SP wearing an OSS as a teaching tool (primary outcome); (2) to evaluate the students' awareness and prejudice against patients with obesity through the encounter (secondary outcome); and (3) describe the advantages and disadvantages when using such a teaching tool.

\section{METHODS \\ Design}

This study is a cross-sectional, proof of concept study using a quantitative questionnaire survey in a simulated role play as part of a regular longitudinal communication course at the Medical Faculty of Tuebingen. The course has a practical orientation with a focus on students trying out approaches in a safe environment shown to foster the consolidation of professional knowledge and behaviour. ${ }^{33-36}$ All second-year medical students from the winter term 2017/18 and the summer term 2018 were

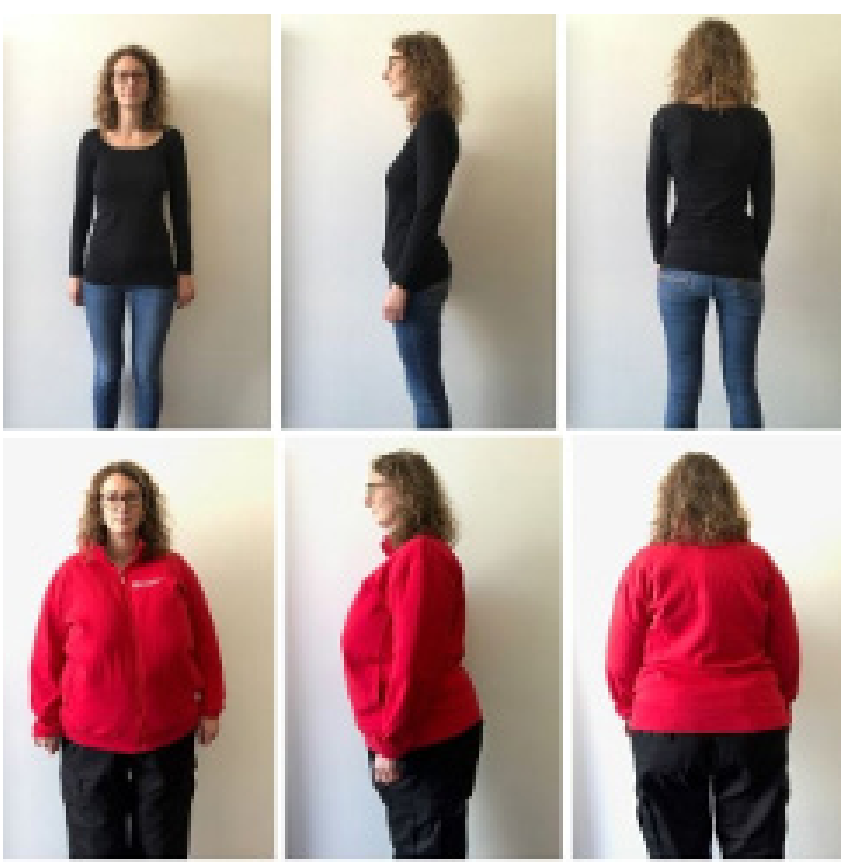

Figure 1 Standardised patient wearing the obesity simulation suit used in the present study to represent a patient with type 2 diabetes and grade 2 obesity. The individual pictured gave written consent for the images to be used.

approached. SPs were all from the faculty's SP programme and were regularly assigned to the communication course. Teachers were experienced clinicians (physician or psychologist) from the Department of Psychosomatic Medicine and Psychotherapy, and Child and Adolescent Psychiatry, respectively. Participation was voluntary, and all participants gave written consent to take part. The students received no incentive.

\section{Patient and public involvement}

No actual patients or members of the public were involved in this study.

\section{Material}

We used an OSS mirroring grade 2 obesity (BMI $35-39.9 \mathrm{~kg} / \mathrm{m}^{2}$ ) from 'Perspectives Pioneers' ('PerspektivenPioniere', Mallersdorf-Pfaffenberg, Bavaria, Germany) (figure 1). The suit consists of two parts: the soft outer shell imitating the typical figure of a patient with obesity, and a series of weights worn inside to simulate the additional weight.

Three different questionnaires for students, teachers and SPs were used. Demographic data were collected from all three groups (gender, age). Teachers evaluated the simulated authenticity (How much does the OSS contribute to a realistic clinical picture?), the didactic profit (How do you evaluate the didactic profit of the OSS regarding the patient-physician-encounter?) and the physical strain (How do you estimate the physical strain for SPs?) (all three items ranging from 1=low to $7=$ veryhigh, respectively) as well as difficulties related to using the suit (free-text). Students also evaluated the 
simulated authenticity and physical strain as well as the degree to which they could empathetically engage in conversation with the SP (items ranging from 1=low to $7=$ veryhigh, respectively). All items were pre-tested and were seen as reliable with Cronbach's $\alpha=0.636$. Teachers and SPs were asked to specifically select items from a list and report the advantages of the OSS for teaching (teachers) and, accordingly, the difficulties encountered when actually wearing the OSS (SPs). Additionally, SPs evaluated the obesity suit concerning its adequacy for role implementation and its physical burden (items ranging from $1=$ low to $7=$ very high, respectively) as well as possible difficulties (free-text).

Furthermore, a figure rating scale presenting single figures with BMI 18 to $42^{37}$ and the subscale 'weight control/blame' of the Anti-Fat Attitudes Test (AFAT) ${ }^{38}$ were used and filled in by all participants.

The $\mathrm{AFAT}^{38}$ is a questionnaire comprising 47 items that are scored on a 5-point Likert-type scale (ranging from $1=$ strongly disagree to $5=$ strongly agree) and was used to assess the negative views of the study participants towards individuals with obesity. The AFAT has three internally consistent factors: 'social/character disparagement', 'physical/romantic unattractiveness', and 'weight control/blame'. As weight control and, accordingly, cognitive attitudes were most relevant to us when dealing with anti-fat attitudes in a medical context, we decided to only use the subscale 'weight control/blame'. Items of that scale were as follows: (1) There is no excuse for being fat; (2) If fat people really wanted to lose weight, they could; (3) Fat people do not necessarily eat more than other people; (4) Most fat people buy too much junk food; (5) Fat people have no will power; (6) The idea that genetics causes people to be fat is just an excuse; (7) If fat people knew how bad they looked, they would lose weight; (8) Most fat people are lazy; (9) Most fat people will latch onto almost any excuse for being fat. Cronbach's $\alpha$ for this shortened version of the scale was $\mathrm{r}=0.792$, representing acceptable reliability for the scale. ${ }^{38}$

\section{Teaching session}

The SP encounter was within the normal basic communication curriculum run by the Department of Psychosomatic Medicine and Psychotherapy. In the proceeding sessions students were familiarised with general communication procedures (eg, taking a complete medical history, handover of patients, etc) as well as specific demands of certain situations (eg, acute case in the emergency department, ward round, communication with patients not speaking German, etc). The session on the OSS is about the role of lifestyle habits and psychosocial factors in widespread diseases like hypertension or diabetes. The SP presents as a patient with type 2 diabetes struggling to keep up with self-care (regular exercise, healthy eating, regular intake of medication) coming for a routine follow-up appointment to her GP. Students as simulated physicians had to take the SP's medical history and explore psychosocial factors related to the diabetes.
Teaching took place in small groups of 10 students, one of whom took on the role of the doctor. Experienced teachers moderated the sessions. Following each session, students, teachers and SPs completed questionnaires anonymously.

To address potential sources of bias we briefed study assistants who were approachable during the survey. Further, we made sure that students could not see the SP without the OSS before their physician-patient encounter.

\section{Data analysis}

Mean $(\mathrm{M}) \pm \mathrm{SD}$ values, frequencies and percentages of relevant factors were calculated. Missing data were replaced by mean. In order to compare the results of the OSS and possible stigmatisation between the different groups, the non-parametric tests Mann-Whitney U test and Kruskal-Wallis test were conducted. The level of significance was $p<0.05$. IBM SPSS Statistics version 24 was used for data analysis. Numbers and percentages refer to valid proportions of answers for any given question. The qualitative data were evaluated by using context analysis. ${ }^{39}$

\section{Ethics}

Ethical approval for the study was given by the Ethics Committee of Tuebingen's Medical Faculty (No. 683/2017BO2). All participants gave their written informed consent. They did not receive a stipend or other forms of compensation for their participation.

\section{RESULTS \\ Sample}

The sample of $\mathrm{n}=246$ participants $(63.8 \%$ female $)$ consisted of students $(\mathrm{n}=207,85.3 \%)$, teachers $(\mathrm{n}=22$, $9.4 \%)$ and SPs $(\mathrm{n}=13,5.3 \%)$. All participants took part in the survey. The only reason for non-participation was missing the teaching altogether. Response Rate of the medical students was $64.7 \%$ (207 of 320). For group-specific means, see table 1.

\section{Results of the OSS}

In regard to the realistic clinical picture, all three groups reported that the OSS contributes to the realistic appearance of a patient with type 2 diabetes $(M=5.62 \pm 1.19)$. There was no significant difference in regard to the realism of the scenario between the groups $\left(\chi^{2}=2.65\right.$; $\mathrm{df}=2 ; \mathrm{p}>0.05)$.

\begin{tabular}{lcl|}
$\begin{array}{l}\text { Table } 1 \\
\text { standardised patients }\end{array}$ & $\begin{array}{l}\text { Demographic data of students, teachers and } \\
\text { Gender } \\
\text { N (\%) }\end{array}$ & $\begin{array}{l}\text { Age } \\
\text { Mean } \pm \text { SD; range }\end{array}$ \\
\hline Students & $207(60.9)$ & $22.54 \pm 4.03 ; 18-55$ years \\
Teachers & $22(81.8)$ & $30.43 \pm 5.18 ; 24-47$ years \\
$\begin{array}{l}\text { Standardised } \\
\text { patients }\end{array}$ & $13(100)$ & $51.46 \pm 5.13 ; 44-56$ years \\
\hline
\end{tabular}


Furthermore, the results showed a significant difference in physical strain for the SPs $\left(\chi^{2}=12.3 ; \mathrm{df}=2 ; \mathrm{p}<0.01\right)$. The teachers $(\mathrm{M}=4.83 \pm 1.23)$ regarded the physical strain for SPs significantly higher compared to the SPs $(\mathrm{M}=3.92 \pm 1.08)$ and the students $(\mathrm{M}=3.82 \pm 1.56)$.

The students tended to agree that the OSS helped them to empathise with the patient who has type 2 diabetes $(\mathrm{M}=4.44 \pm 1.61)$. The teachers evaluated the didactic value added as quite high $(\mathrm{M}=5.63 \pm 1.41)$.

\section{Advantages and challenges of the OSS}

In free text questions, students, teachers and SPs were first asked about their general remarks about the use of the OSS. Students reported that the look of the OSS impacted them and activated possible stereotypes. A few students $(12 \%)$ reported that it was difficult to talk about the patient's weight. Students suggested using some of the class time to talk about reservations in regard to people with obesity (eg, missing compassion, disgust, lack of concept of disease) and how to deal with them professionally. In general, most of the students $(65 \%)$ remarked that the OSS made the role play more realistic and aligned with the clinical picture. In free text, teachers supported further use of the OSS in teaching, but criticised the items chosen from the AFAT in the present study as being too negative, one-sided, and stigma-eliciting. They were unsure whether the diabetes case was too difficult for the students who participated in the present study. SPs mainly $(75 \%)$ made specific comments regarding the practicability of the OSS; they first pointed out the importance of matching the clothing style of the SP with the story line of the patient's role, and second, they made suggestions about improving clothing (eg, using stretch trousers instead of jeans with buttons to hasten the change of clothes between role plays). Among the teachers, $87.0 \%$ reported that the OSS was authentic. Almost three-quarters of the teachers $(73.9 \%)$ thought that the OSS facilitated empathising with the patient in the role play, while $43.5 \%$ of them felt that the OSS contributed to making the SP more convincing. In regard to wearing the OSS, $53.8 \%$ of SPs reported that the heat within the OSS was challenging. Furthermore, $23.1 \%$ of them stated that its weight and the process of putting it on and taking it off were problematic.

\section{Body impression}

Regarding body impression of the OSS, the SPs estimated the BMI of the OSS as highest, with $\mathrm{M}_{\mathrm{BMI}}=41.25 \pm 1.86 \mathrm{~kg} /$ $\mathrm{m}^{2} \quad(\mathrm{p}<0.001)$. The students and teachers evaluated the level of obesity of the OSS correctly as grade 2 obesity (students: $\mathrm{M}_{\mathrm{BMI}}=38.00 \pm 3.01 \mathrm{~kg} / \mathrm{m}^{2}$; teachers: $\left.\mathrm{M}_{\mathrm{BMI}}=39.18 \pm 2.90 \mathrm{~kg} / \mathrm{m}^{2}\right)$.

\section{The AFAT and possible stigmatisation}

All three groups mostly disagreed with the items of the AFAT when looking at the mean value across all items for all groups $(M=2.18 \pm 0.56)$. Significant differences between groups could be found for five items of the AFAT in particular (for details see table 2). Students were mostly neutral regarding the statement 'Fat people could lose weight if they really wanted to'; SPs tended to disagree with this statement the most. Furthermore, the SPs and students tended to agree that 'Fat people do not necessarily eat more than others' (variable recoded in table 2). Teachers felt slightly different towards this statement and responded slightly more neutral to it. Regarding the item 'Most fat people are lazy', teachers disagreed significantly more with the statement compared with students and SPs. Although there was a significant difference between the three groups for the statements 'Most fat people will latch onto almost any excuse for being fat' and 'The idea that genetics causes people to be fat is just an excuse', all three groups tended to disagree or strongly disagree with these statements (mean values for all groups between 1 and 2).

\section{DISCUSSION}

In the present study, medical students had to interact with an SP with type 2 diabetes wearing an OSS with the aim of developing a more realistic view of the physical and psychological implications of overweight and obesity and further reflecting on potential prejudices towards patients with obesity. Based on the results of the present study, the OSS contributes to a realistic perception of the patient group depicted in a role play of a patient with obesity and type 2 diabetes according to SPs, students and teachers. The physical strain of having to wear an OSS was rated medium by SPs, students and teachers. Teachers rated the physical strain as being significantly higher than the other two groups, which might possibly be due to the fact that, as experienced clinicians, they might be more aware of the physical strains reported by patients with obesity during daily consultation hours. The BMI estimation by SPs, students and teachers is over $30 \mathrm{~kg} / \mathrm{m}^{2}$ — thus, by definition, in the range of obesity. Interestingly, the BMI estimation was significantly higher in SPs, who were actually wearing the suit, compared with students and experienced clinicians. This shows that for evaluation of such an extraordinary teaching tool like an OSS, taking into account the perspectives of all parties involved provides valuable insight. Besides a better understanding of the application in general, curriculum designers can also use such information for strategic planning (eg, deciding which actors can bear the physical strain).

Regarding the AFAT, students demonstrated significantly stronger anti-fat prejudices compared with SPs or teachers-underlining the need for specialised teaching modules. Clinicians from various disciplines have also been shown to have prejudices towards patients with obesity, even when working with them on a daily basis. ${ }^{13}$ In this study, teachers were all experienced clinicians from the Department of Psychosomatic Medicine and Psychotherapy or Child and Adolescent Psychiatry. Similar studies showed that with experience and thus background knowledge of the underlying causes of obesity, understanding is enhanced and thus prejudices 
Table 2 Results per group (students, teachers and standardised patients (SP)) for the Anti-Fat Attitudes Test (AFAT).

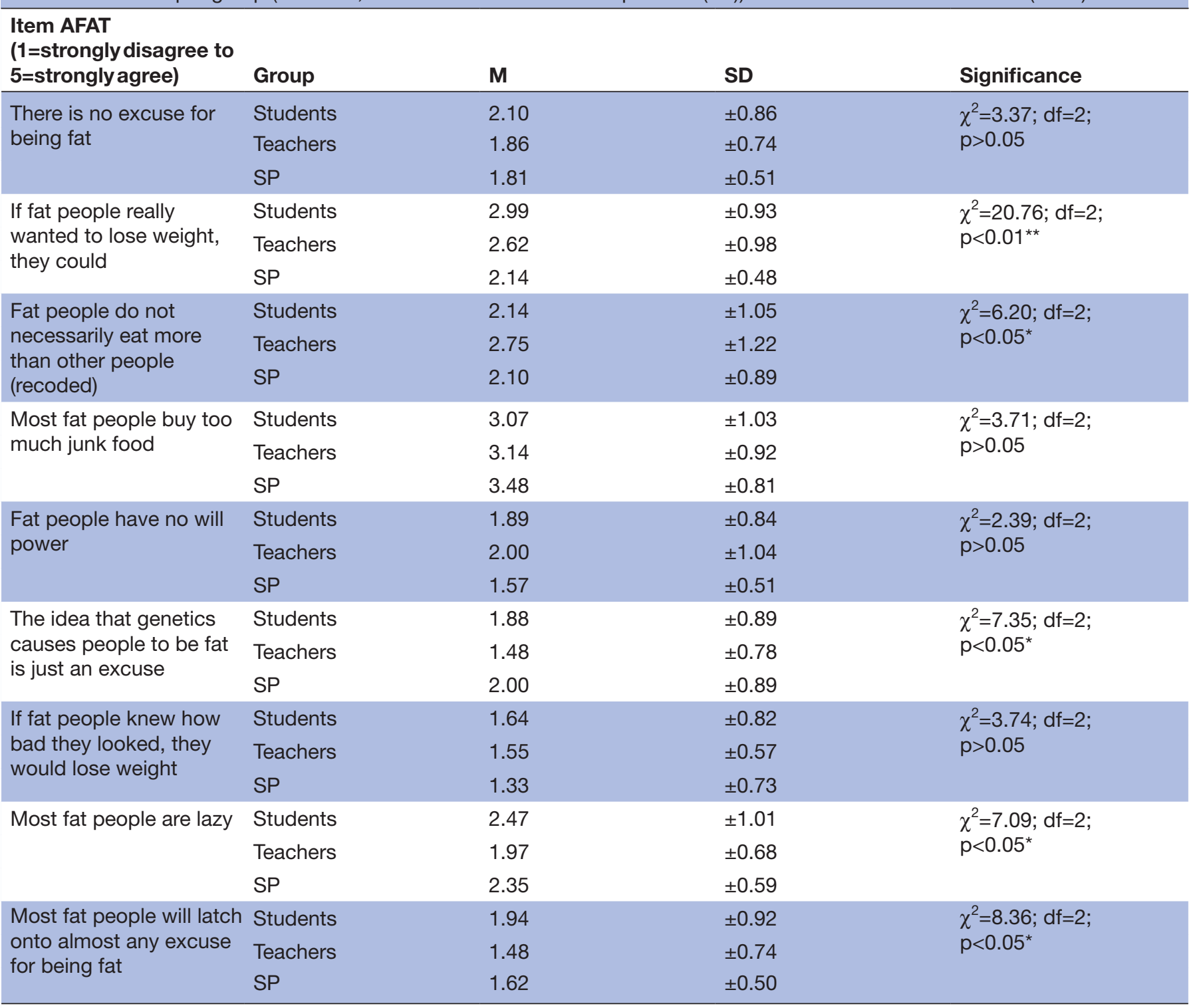

${ }^{*} \mathrm{p}<0.05 ;{ }^{* *} \mathrm{p}<0.01$

are reduced..$^{21} 4041$ Students, however, agreed significantly stronger with the items 'Fat people could lose weight if they really wanted to' and 'Most fat people are lazy' compared to the two other subgroups of study participants. This is in line with the results reported by Miller et $a t^{42}$ who found an implicit anti-fat bias in more than one-third of the medical students in their study-with only a few of them being aware of it.

Students needs to reflect further on stigmatisation, and prejudice against certain patient groups might also be reflected in their desire for a discussion about reservations regarding the patient group in class when answering the free-text field.

Specifically regarding the issue of obesity, Miller $e t a t^{42}$ recommended "Medical schools' obesity curricula should address weight-related biases and their potential impact on care". They strongly support working on implicit biases with medical students from the early stages of their education onward.

Further studies should focus on long-term assessments of anti-fat attitudes. In Kushner et $a l,^{32}$ for example, it was shown that "in contrast to empathy and counselling, scaled stereotyping mean scores showed a regression back to baseline over a year" - which, to an even greater degree, supports the need for research to focus on variables that support lasting effects of anti-stereotyping interventions. Regarding future research methods on 'anti-fat' attitudes, Carl and colleagues ${ }^{43}$ suggest the use of a video instrument, which has just been validated within a pilot study.

Moreover, the distinction between explicit and implicit biases should be the focus of attention when working with SPs wearing the OSS, because Sabin et at found that there is only a weak correlation between explicit and implicit weight bias, thus arguing for these to be 
considered separately. Also, the work of Leehr et al, ${ }^{10}$ who observed gaze behaviour in their participants, speaks for the necessity of additionally investigating an implicit 'anti-obesity' bias.

There are several limitations to the present study. A potential limitation of validity could be the fact that only female SPs were used and thus gender-specific differences could not be taken into account. However, for the purpose of the study we explicitly did not want to add a further level of complexity and thus stuck to one gender only. Additionally, the study noted that students were biased towards patients with obesity and that they found the OSS realistic for a simulated encounter. However, it is beyond the scope of this study to address the reduction of bias by using an OSS, which would need to be examined in a pre-post test setting.

To guarantee a realistic scenario, a considerate choice of clothing style for the SP wearing the OSS seems to be crucial. Furthermore, the short version of the AFAT used in the present study was criticised as being 'too negative' and its intentions as 'too obvious' by participants. We agree to some extent but we want to refer to the original paper by Lewis and colleagues ${ }^{38}$ and, accordingly, the subscale's good reliability as also shown in the present study.

Despite these limitations, we strongly believe that integrating an OSS into the routine undergraduate medical teaching context is a valuable tool. It can raise medical students' awareness for communication encounters with patients with obesity. This has also been successfully shown for other disabilities in the simulated environment with partially, even complete, curricula for this topic. ${ }^{45-48}$

\section{Outlook}

As this study established that the OSS contributes to a realistic appearance of patients with obesity, this kind of simulation can be used to address the issue of stigmatisation more specifically. Here, pre-post testing of the AFAT in such a simulated encounter is necessary. Alternatively, SPs with or without OSS or SPs being actual persons with obesity could be compared.

Contributors AHW was responsible for the design and conduct of the study, as well as acquisition, analysis and interpretation of data. She drafted the first version of the manuscript. TL and RE were involved in data acquisition, analyses and interpretation, and revised the manuscript critically. FJ was responsible for the teaching and revised the manuscript critically. LMW and SZ made substantial contributions to the study design and revised the manuscript critically. All authors approved the final version of the manuscript and agreed to be accountable for all aspects of the work.

Funding We acknowledge support with financing publication fees by Deutsche Forschungsgemeinschaft and Open Access Publishing Fund of the University of Tuebingen.

Competing interests None declared.

Patient consent for publication Not required.

Ethics approval Ethical approval for the study was given by the Ethics Committee of Tuebingen's Medical Faculty (No. 683/2017B02). All procedures performed in studies involving human participants were in accordance with the ethical standards of the institutional and/or national research committee and with the 1964 Helsinki declaration and its later amendments or comparable ethical standards.
Provenance and peer review Not commissioned; externally peer reviewed.

Data sharing statement No additional data are available.

Open access This is an open access article distributed in accordance with the Creative Commons Attribution Non Commercial (CC BY-NC 4.0) license, which permits others to distribute, remix, adapt, build upon this work non-commercially, and license their derivative works on different terms, provided the original work is properly cited, appropriate credit is given, any changes made indicated, and the use is non-commercial. See: http://creativecommons.org/licenses/by-nc/4.0/.

\section{REFERENCES}

1. Mensink GBM, Schienkiewitz A, Haftenberger M, et al. Übergewicht und Adipositas in Deutschland: Ergebnisse der Studie zur Gesundheit Erwachsener in Deutschland (DEGS1). Bundesgesundheitsblatt, Gesundheitsforschung, Gesundheitsschutz 2013;56(5-6):786-94.

2. Kopelman P. Health risks associated with overweight and obesity. Obes Rev 2007;8 Suppl 1:13-17.

3. Guh DP, Zhang W, Bansback N, et al. The incidence of comorbidities related to obesity and overweight: a systematic review and meta-analysis. BMC Public Health 2009;9:88.

4. Pischon $\mathrm{T}$, Boeing $\mathrm{H}$, Hoffmann $\mathrm{K}$, et al. General and abdominal adiposity and risk of death in Europe. N Engl J Med 2008;359:2105-20.

5. Wardle J, Cooke L. The impact of obesity on psychological wellbeing. Best Pract Res Clin Endocrinol Metab 2005;19:421-40.

6. Statistik-Portal S-D. Prognostizierter Anteil adipöser Erwachsener (Fettleibigkeit*) in ausgewählten Ländern nach Geschlecht im Jahr 2025. 2018. NCD-RisC https://de.statista.com/statistik/daten/studie/ 582427/umfrage/anteil-adipoeser-erwachsener-fettleibigkeit-nachlaendern-und-geschlecht/ (Accessed 30 Oct 2018).

7. Hilbert A, Ried J, Zipfel S, et al. Folgeerkrankungen. Therapie 2013;7:150-3.

8. Puhl RM, Heuer CA. The stigma of obesity: a review and update. Obesity 2009;17:941-64.

9. Giel KE, Zipfel S, Alizadeh M, et al. Stigmatization of obese individuals by human resource professionals: an experimental study. BMC Public Health 2012;12:525.

10. Leehr E, Giel KE, Schaeffeler N, et al. Where do you look? Visual attention to human bodies across the weight spectrum in individuals with normal weight or with obesity. Obes Facts 2018;11:277-86.

11. Gudzune KA, Bleich SN, Richards TM, et al. Doctor shopping by overweight and obese patients is associated with increased healthcare utilization. Obesity 2013;21:1328-34.

12. Gudzune KA, Bennett WL, Cooper LA, et al. Prior doctor shopping resulting from differential treatment correlates with differences in current patient-provider relationships. Obesity 2014;22:1952-5.

13. Hebl MR, JJljoo X. Weighing the care: physicians' reactions to the size of a patient. 2001;25:1246.

14. Phelan SM, Burgess DJ, Yeazel MW, et al. Impact of weight bias and stigma on quality of care and outcomes for patients with obesity. Obes Rev 2015;16:319-26.

15. Brown I. Nurses' attitudes towards adult patients who are obese: literature review. J Adv Nurs 2006;53:221-32.

16. Teachman BA, Brownell KD. Implicit anti-fat bias among health professionals: is anyone immune? Int $\mathrm{J}$ Obes Relat Metab Disord 2001;25:1525-31.

17. Diversi TM, Hughes R, Burke KJ. The prevalence and practice impact of weight bias amongst Australian dietitians. Obes Sci Pract 2016;2:456-65.

18. Stone $\mathrm{O}$, Werner $\mathrm{P}$. Israeli dietitians' professional stigma attached to obese patients. Qual Health Res 2012;22:768-76.

19. Cavaleri R, Short T, Karunaratne S, et al. Weight stigmatisation in physiotherapy: a systematic review. Physical Therapy Reviews 2016;21:1-9.

20. Wang SS, Brownell KD, Wadden TA. The influence of the stigma of obesity on overweight individuals. Int J Obes Relat Metab Disord 2004;28:1333-7.

21. Schwartz MB, Chambliss HO, Brownell KD, et al. Weight bias among health professionals specializing in obesity. Obes Res 2003;11:1033-9.

22. Fraser K, McLaughlin K. Can we avoid the guilt of shame in medical education? Med Educ 2014;48:1036-8.

23. Bokken L, Rethans JJ, van Heurn L, et al. Students' views on the use of real patients and simulated patients in undergraduate medical education. Acad Med 2009;84:958-63.

24. Simek-Downing L, Quirk ME, Letendre AJ. Simulated versus actual patients in teaching medical interviewing. Fam Med 1986;18:358-60. 
25. Meadows A, Daníelsdóttir S, Calogero R, et al. Why fat suits do not advance the scientific study of weight stigma. Obesity 2017;25:275-75.

26. Wald J. McDonald's obesity suit tossed: US judge says complaint fails to prove chain is responsible for kids' weight gain. CNN Online, money cnn com 2003.

27. Rahrer AP. Designing and Creating the Oregon State Age and Disability Simulation Suit, 2013.

28. Tremayne P, Burdett J, Utecht C. Simulation suit aids tailored care. Nurs Older People 2011;23:19-22.

29. Hales C, Gray L, Russell L, et al. A qualitative study to explore the impact of simulating extreme obesity on health care professionals attitudes and perceptions. Ostomy Wound Manage 2018;64:18-24.

30. Mills CD, Dee S. Challenging perceptions on body image using a bariatric weighted suit with female university dancers. Journal of Obesity and Bariatrics 2016;3:1-6.

31. Thiem P. Instant Adipositas. Julius-Maximilians-Universität Würzburg, 2012.

32. Kushner RF, Zeiss DM, Feinglass JM, et al. An obesity educational intervention for medical students addressing weight bias and communication skills using standardized patients. BMC Med Educ 2014;14:53.

33. Gruber $H$, Mandl $H$, Renkl A. Was lernen wir in Schule und Hochschule: Träges Wissen? Mandl JG H, ed. Die Kluft zwischen Wissen und Handeln. Göttingen: Hogrefe, 2000:139-56.

34. von Cranach $M$, Bangerter $A$. Wissen und Handeln in systemischer Perspektive. Mandl JG H, ed. Die Kluft zwischen Wissen und Handeln. Göttingen: Hogrefe, 2000:139-56.

35. Pfäffli B. Lehren an Hochschulen - Eine Hochschuldidaktik für den Aufbau von Wissen und Kompetenzen. Bern: Haupt Verlag, 2005:189.

36. Meyerhoff J, Brühl C. Fachwissen lebendig vermitteln - Das Methodenhandbuch für Trainer und Dozenten. Leonberg: Rosenberger Fachverlag, 2004:133.

37. Mölbert SC, Thaler A, Streuber S, et al. Investigating body image disturbance in anorexia nervosa using novel biometric figure rating scales: a pilot study. Eur Eat Disord Rev 2017;25:607-12.

38. Lewis RJ, Cash TF, Jacobi L, Bubb-Lewis C, et al. Prejudice toward fat people: the development and validation of the antifat attitudes test. Obes Res 1997;5:297-307.

39. Mayring P. Qualitative inhaltsanalyse: Handbuch qualitative Forschung in der Psychologie: Springer, 2010:601-13.

40. Bocquier A, Verger P, Basdevant A, et al. Overweight and obesity: knowledge, attitudes, and practices of general practitioners in France. Obes Res 2005;13:787-95.

41. Puhl RM, Latner JD, King KM, et al. Weight bias among professionals treating eating disorders: attitudes about treatment and perceived patient outcomes. Int J Eat Disord 2014;47:65-75.

42. Miller DP, Spangler JG, Vitolins MZ, et al. Are medical students aware of their anti-obesity bias? Acad Med 2013;88:978-82.

43. Carl J, Thedinga HK, Zipfel S, et al. Stimulating weight stigma in future experimental designs on physical activity - development and pilot validation of a video instrument. Obes Facts 2018;11:206-20.

44. Sabin JA, Marini M, Nosek BA. Implicit and explicit anti-fat bias among a large sample of medical doctors by BMI, race/ethnicity and gender. PLoS One 2012;7:e48448.

45. Graham MCL, Brown RS, Zhen H, et al. Teaching medical students about disability in family medicine. 2009;41:542.

46. Duggan A, Bradshaw YS, Carroll SE, et al. What can I learn from this interaction? A qualitative analysis of medical student self-reflection and learning in a standardized patient exercise about disability. Journal of Health Communication 2009;14:797-811.

47. Eddey G, Robey K. Increasing medical student's self-perceived skill and comfort in examining persons with severe developmental disabilities: the use of standardized patients who are nonverbal due to cerebral palsy. 1998 Academic Medicine;73(10 Suppl):S106-8.

48. Long-Bellil LM, Robey KL, Graham CL, et al. Teaching medical students about disability: The use of standardized patients. Academic Medicine 2011;86:1163-70. 